\title{
APLICATIVOS ÚTEIS: \\ UM PROCESSO DE ENSINO - APRENDIZAGEM \\ APLICADO ÀS NECESSIDADES DO COTIDIANO
}

A TEACHING PROCESS - LEARNING APPLIED TO THE DAILY NEEDS

\author{
APLICACIONES ÚTILES: \\ UN PROCEDIMIENTO DE ENSEÑANZA - APRENDIZAJE \\ APLICADO A LAS NECESIDADES DEL COTIDIANO
}

\section{Adriana da Silva Jacinto ${ }^{1}$ \\ Alice Nardoni Marteli ${ }^{2}$ \\ João Gabriel Dias Pires ${ }^{3}$ \\ Jaqueline da Silva Jacinto 4}

\begin{abstract}
RESUMO: O produto do ensino deveria ser a aprendizagem efetiva, eficaz e significativa. No entanto, em pleno século XXI, é notório que existem as mais variadas dificuldades de ensino e de aprendizagem. As novas tecnologias computacionais têm sido apontadas como um fator que pode trazer benefícios ao processo de ensino e aprendizagem, contudo é preciso que elas sirvam de suporte a novas estratégias pedagógicas. O problema reside, então, em como desenvolver e aplicar novas estratégias pedagógicas, de forma que o aluno se sinta comprometido com o seu processo de ensino-aprendizagem. Este artigo propõe um processo de ensinoaprendizagem que une o uso de smartphones, programação de aplicativos e raciocínio crítico sobre os problemas que o aluno vislumbra em seu cotidiano. Tal processo foi aplicado a alunos de graduação do curso de Tecnologia em Banco de Dados. Dentre os resultados obtidos, houve o desenvolvimento de um aplicativo colaborativo para auxiliar o gerenciamento de riscos de desastres ambientais de cunho hidrometeorológico. Esse aplicativo tem por intuito alertar órgãos responsáveis para que possam tomar medidas preventivas para a evacuação de áreas de risco, de modo mais rápido que o comumente usado.
\end{abstract}

PAlaVRAS-ChavE: Educação. Computação. Realidade. Cotidiano.

ABSTRACT: The outcome of Education should be efficient, effective and meaningful learning. However, in the 21 st century, it is well known that there are many difficulties in teaching and learning. New computational technologies are pointed out as a factor that can bring benefits to the teaching and learning process, since they should support new pedagogical strategies. So, the problem lies in how to develop and apply new pedagogical strategies in order to make student aware about his responsibility for his own teaching-learning process. This article proposes a teaching-learning process that unites the use of smartphones, application programming and critical reasoning about problems that the student sees in his daily life. This process was applied to undergraduate students of the Database Technology course and. Among the obtained results, there was the development of a collaborative application to help manage the risks of hydro - meteorological environmental disasters. This application is intended to alert responsible agencies in order to they can take preventive attitudes to evacuate areas at risk, more quickly than commonly used. This and other results indicate the validity of the proposal

KEYWORDS: Education. Computation. Reality. Daily Needs.

Submetido em: 28/03/2018 - Aceito em: 02/05/2018 - Publicado em: 29/05/20018.

\begin{tabular}{l|l|l|l|l|l} 
(C) Rev. Inter. Educ. Sup. & Campinas, SP & v.4 & n.3 & p.610-630 & set./dez. 2018
\end{tabular}


RESUMEN: El producto de la enseñanza debería ser el aprendizaje efectivo, eficaz y significativo. Sin embargo, en pleno siglo XXI, es notorio que existen las más variadas dificultades de enseñanza y de aprendizaje. Las nuevas tecnologías computacionales se han apuntado como un factor que puede traer beneficios al proceso de enseñanza y aprendizaje, pero es necesario que sirven de soporte a nuevas estrategias pedagógicas. El problema reside entonces en cómo desarrollar y aplicar nuevas estrategias pedagógicas, de forma que el alumno se sienta comprometido con su proceso de enseñanza-aprendizaje. Este artículo propone un proceso de enseñanzaaprendizaje que une el uso de smartphones, programación de aplicaciones y raciocinio crítico sobre los problemas que el alumno vislumbra en su cotidiano. Este proceso fue aplicado a alumnos de graduación del curso de Tecnología en base de datos. Entre los resultados obtenidos, hubo el desarrollo de una aplicación colaborativa para auxiliar la gestión de riesgos de desastres ambientales de cuño hidrometeorológico. Esta aplicación tiene por objeto alertar a los órganos responsables de que puedan tomar medidas preventivas para la evacuación de áreas de riesgo, de manera más rápida que la comúnmente utilizada. Este y otros resultados obtenidos indican la validez de la propuesta.

PALABRAS Clave: Educación. Computación. Realidad. diario

\section{INTRODUÇÃO: O PROCESSO DE ENSINO-APRENDIZAGEM NO SÉCULO XXI}

O produto do ensino deveria ser a aprendizagem efetiva, eficaz e significativa. Aprendizagem efetiva no que tange aos alunos realmente aprenderem o que lhes foi ensinado. No que diz respeito ao termo eficaz, os alunos seriam capazes de aplicar os conceitos aprendidos na resolução de problemas. E, finalmente, a aprendizagem seria significativa, se o alunado apreendesse os conceitos básicos de determinado tópico do conhecimento, apropriando-se deles de forma permanente. De forma mais específica, o produto do ensino superior deveria ser um indivíduo que demonstrasse uma atuação inovadora, empreendedora, criativa, eficiente e competitiva (PENSIN, 2018).

No entanto, no século XXI, é notório que, ainda, existem as mais variadas dificuldades de ensino e de aprendizagem, situação ilustrada pela alta taxa de evasão que ocorre no ensino superior. No Brasil, apesar das políticas públicas implementadas pelo Estado, a fim de ampliar e facilitar o acesso ao ensino superior, o que de fato vem ocorrendo, mais da metade dos alunos ingressantes não conclui sua graduação (LIMA; ZAGO, 2018).

Há diversos trabalhos (JORGE et al., 2016; LIMA; ZAGO, 2018; NETO et al., 2015; SALES; LEAL, 2018; SILVA, S. V. Da, 2016), que tratam deste assunto, isto é, sobre as dificuldades de ensino e de aprendizagem, ora investigando as causas, ora propondo alternativas de solução para o problema. Dentre as causas estudadas, uma delas seria a fragilização do vínculo ou da relação que o aluno mantém com a instituição de ensino, algo que pode ser agravado pela não incorporação de tecnologias computacionais no currículo escolar (SALES; LEAL, 2018). Esta afirmação está fundamentada na observação de que o aluno contemporâneo, por vezes, se dispersa com facilidade em contextos de aulas exclusivamente tradicionais e expositivas (FRAGELLI, 2017). 
Em geral, o uso de computadores, smartphones, internet e outras tecnologias computacionais são apontados como um fator que pode trazer benefícios ao processo de ensino e aprendizagem (NOGARO; CERUTTI, 2016; SALES; LEAL, 2018). Um dos destaques em Educação, que concordam com essa ideia, é o professor Mário Sérgio Cortella, conforme entrevista que ele cedeu a um jornal. Cortella diz (REIS, 2014):

É preciso incorporar o que elas já fazem. A geração anterior, de quem já tem mais de 30 anos, só se comunicava pelo telefone. Esta geração de crianças e jovens voltou a escrever - no Facebook, no Twitter, no WhatsApp, em blogs. A escola tem de aproveitar essa produção. (REIS, 2014, p. 1)

Contudo, nem sempre o professorado está preparado para utilizar de forma adequada tais ferramentas, isto é, fazendo com que elas sirvam de suporte a novas estratégias pedagógicas (FERREIRA; FREITAS, R. C.; MOREIRA, 2018; MARIM; FREITAS, A. V.; SANTOS, H. Da S., 2014; NOGARO; CERUTTI, 2016). De forma mais incisiva, há, inclusive, relatos de professores universitários que classificam as tecnologias computacionais como ameaçadoras, pois eles se sentem incomodados com o fato de os alunos estarem sempre olhando seus smartphones durante as aulas (SALES; LEAL, 2018). Tal sensação de incômodo perpassa pela questão de quem detém o conhecimento. O professor deixou de ser a única fonte de conhecimento e informação, pois os alunos podem acessar sites durante as aulas e obter as informações desejadas.

Considerando a intensificação do uso de tecnologias computacionais e o desconforto de vários professores em relação a elas, há uma disparidade. A fim de tratar esta situação, várias modificações nos currículos de educação básica e superior são necessárias, fazendo com que eles sejam compostos por práticas analógicas e práticas computacionais (SALES; LEAL, 2018).

Em outras palavras, é necessário modificar a situação em que professores precisam dizer aos alunos "guardem os smartphones, pois a aula vai começar". O cenário ideal seria aquele no qual os alunos se sentissem instigados a resolver questões relacionadas ao seu cotidiano. E, para superar os desafios propostos, conceitos seriam aprendidos e ferramentas seriam utilizadas, incluindo as tecnologias computacionais, tais como os smartphones.

Obter esse cenário ideal não é um algo trivial, pois constitui-se em uma ruptura de paradigma, no qual as práticas curriculares tradicionais são baseadas no silêncio, na concentração máxima, na realização de uma tarefa por vez (SALES; LEAL, 2018) e na transmissão e memorização de informações (ARAÚJO; BELIAN, 2018). Além disso, há de se cuidar para que as tecnologias computacionais não sejam usadas, meramente, para apoiar práticas pedagógicas conduzidas e focalizadas na transmissão de conhecimento (FERREIRA; FREITAS, R. C.; MOREIRA, 2018). 
Todavia, apesar de existirem contingências tais como falta de tempo, carência de formação específica ou de recursos, a maioria dos professores universitários demonstra forte comprometimento com o processo de ensino e aprendizagem (FERREIRA; FREITAS, R. C.; MOREIRA, 2018). Tais professores desejam que seus alunos tornem-se atores principais e proativos na aquisição das competências profissionais necessárias (ARAÚJO; BELIAN, 2018; FERREIRA; FREITAS, R. C.; MOREIRA, 2018).

Considerando o cenário ideal descrito e a dificuldade de obtê-lo, este artigo descreve uma proposta de processo de ensino e aprendizagem que contempla a busca por soluções para problemas do cotidiano e uso de tecnologias computacionais, por meio do uso de metodologias ativas. Tal proposta foi aplicada a alunos de graduação do curso de Tecnologia em Banco de Dados e, dentre os vários resultados obtidos e aplicativos gerados, desenvolveuse uma solução chamada Urban Flooding App. Esse aplicativo para dispositivo móveis tem por intuito alertar a sociedade sobre a ocorrência de catástrofes ambientais, além de poder auxiliar na implementação de políticas públicas.

O presente artigo contém as seções descritas a seguir. A Seção intitulada Fundamentação Teórica contém conceitos importantes utilizados na proposta deste artigo. Na Seção Trabalhos Relacionados há uma comparação entre alguns trabalhos e a proposta ora apresentada. A Seção Proposta: Aplicativos Úteis descreve os detalhes da proposta de processo de ensino e aprendizagem, aplicada aos alunos de graduação, do curso de Tecnologia em Banco de Dados. A Seção Resultados Obtidos descreve as etapas do processo referentes à geração de um dos aplicativos resultantes, o Urban Flooding App. Finalizando, a última seção apresenta as considerações finais deste trabalho.

\section{FUNDAMENTAÇÃO TEÓRICA}

Metodologias ativas valorizam a participação efetiva dos alunos na construção do conhecimento e no desenvolvimento de competências, com mediação de professores e uso de ferramentas do mundo digital (BACICH; MORAN, 2018). Tal abordagem valoriza o protagonismo dos alunos, desafiando-os a tomar decisões. Dentre as estratégias ou práticas pedagógicas que compartilham este mesmo ideal, este trabalho destaca os termos Interdisciplinaridade, Aprendizagem Baseada em Problema (Problem Based Learning - PBL), Aprendizagem Orientada a Projetos e Aprendizagem Significativa, devido à proximidade dos conceitos, inerentes nessas abordagens, com a proposta descrita neste artigo.

Os modelos, que adotam metodologias ativas, estão mais centrados em aprender ativamente com problemas reais, desafios relevantes, jogos, atividades, leituras e projetos (MORAN, 2013). Para que o aluno resolva um problema real, é preciso que ele o entenda e domine os

\begin{tabular}{|l|l|l|l|l|l|}
\hline (C) Rev. Inter. Educ. Sup. & Campinas, SP & v.4 & n.3 & p.610-630 & set./dez. 2018 \\
\hline
\end{tabular}


diversos conceitos que permeiam o problema. Todos estes conceitos não são contemplados em apenas uma disciplina de um curso, fazendo com que seja necessária a prática da interdisciplinaridade.

Não há um consenso sobre a definição de interdisciplinaridade, mas ela pode ser considerada como uma prática pedagógica que une duas ou mais disciplinas, retomando o caráter de interdependência e interatividade existente entre eventos, conceitos e ideias (THIESEN, 2008). O uso de interdisciplinaridade resgata a visão de contexto da realidade, propiciando ao aluno perceber que conceitos e teorias estão conectados entre si, isto é, as partes compõem o todo de um problema real. A utilização de interdisciplinaridade viabiliza a PBL e a Aprendizagem Orientada a Projetos.

Na PBL, utilizam-se problemas do mundo real e estudos de casos hipotéticos, de forma que o aluno seja desafiado a resolvê-los e, para cumprir esse objetivo, os conteúdos planejados precisam ser assimilados (MELO-SOLARTE; BARANAUSKAS, [s.d.]). A PBL inspira-se nos princípios da escola ativa, do método científico, na integração de conteúdos e áreas envolvidas, em que os alunos aprendem a aprender e se preparam para resolver problemas relacionados às suas futuras profissões (MORAN, 2013).

A Aprendizagem Orientada a Projetos possui um caráter mais amplo e multifacetado, sendo que projeto se refere a uma tarefa complexa, cuja finalização resulta em um produto ou apresentação (NOGUEIRA; MARTINEZ; OLIVEIRA, 2016). Durante o processo, os alunos envolvem-se com questões interdisciplinares, tomam decisões e agem sozinhos e em equipe. Nessa abordagem, há um cenário propício para que ocorra a melhoria do pensamento crítico, da criatividade e da percepção de que existem várias maneiras para a realização de uma mesma tarefa (MORAN, 2013). Em cada etapa de execução do projeto, o aluno é avaliado.

A finalidade do uso dessas abordagens é fazer com que o aluno adquira uma aprendizagem significativa, isto é, que se estabeleça uma interação seletiva entre os novos tópicos de aprendizagem e os conhecimentos preexistentes na sua estrutura cognitiva (AUSUBEL, 2003). Em outras palavras, o aluno soma novos conhecimentos aos que ele já possui. Por meio da aprendizagem significativa é que o aluno retém de forma permanente um ensinamento, contudo é necessário que esse aluno tenha uma disposição ou motivação para aprender (SILVA JR., 2017), ambiente propício para o emprego de projetos e problemas desafiadores.

\section{TRABALHOS RELACIONADOS}

Explorando as teorias apresentadas, alguns trabalhos apresentam resultados interessantes. No trabalho de NOGUEIRA; MARTINEZ; OLIVEIRA (2016), as autoras descrevem as etapas 
de um projeto interdisciplinar para o desenvolvimento de jogos computacionais, para aprendizagem de inglês, dedicados à Educação Básica. Nas considerações finais, as autoras destacam que as professoras perceberam que os alunos adquiriram uma aprendizagem mais significativa, porque eles lidaram com tarefas concretas, do mundo real, sendo mais intimamente ligadas ao mundo social do aluno (NOGUEIRA; MARTINEZ; OLIVEIRA, 2016).

Analisando a abordagem anteriormente descrita e comparando à proposta apresentada neste trabalho, há algumas diferenças: a) naquele trabalho, o aluno recebeu um problema e, na abordagem deste artigo, o próprio aluno deve analisar a realidade que o cerca e encontrar um problema passível de solução computacional; b) naquele trabalho, apenas duas disciplinas foram arroladas no projeto, enquanto que, na abordagem aqui apresentada, mais disciplinas são afetadas; c) o público alvo para os jogos de todos os alunos restringe-se aos alunos do Ensino Médio, enquanto que nesta proposta, o aluno deve escolher seu público alvo; d) naquela abordagem, diferentemente da proposta ora apresentada, somente a implementação de jogos foi permitida.

As diferenças mencionadas podem proporcionar ganhos na aprendizagem do aluno. Por exemplo, desde o início, na proposta deste trabalho, o aluno sente-se responsável pela sua aprendizagem, pois o problema tratado foi identificado por ele e, por conseguinte, o próprio aluno desejou cuidar daquele assunto. Também, as capacidades de análise, síntese e argumentação devem aflorar-se no aluno, pois ele terá de convencer a audiência de que aquilo que ele quer abordar é realmente um problema, digno de ser tratado.

Outro trabalho relata a experiência feita com alunos de Ensino Médio, em um curso introdutório de programação (PERDIKURI, 2014). O artigo conta que os alunos tiveram facilidade para criar aplicativos para tablets e smartphones, tanto os sugeridos pelo professor, segundo uma certa especificação, quanto outros tipos de aplicativos por iniciativa própria. Apesar daquele trabalho não ter uma vertente interdisciplinar e nem ter como foco as práticas pedagógicas em si, tal relato vem corroborar a ideia, ora também aqui defendida, de que a incorporação de tecnologias computacionais pode trazer benefícios à aprendizagem, desde que sejam aplicadas as estratégias pedagógicas adequadas.

Em trabalhos anteriores, o uso de interdisciplinaridade e da aprendizagem baseada em problema são temas investigados pelos autores. De formas diversas, temos comprovado sua utilidade e eficiência. A novidade deste trabalho aqui relatado é a agregação dessa prática a problemas do cotidiano e à programação de aplicativos para dispositivos móveis, tais como smartphone e tablets. 


\section{PROPOSTA: APLICATIVOS ÚTEIS}

Considerando que a disciplina Laboratório de Aprendizagem II (Lab II) tem o papel de fazer com que o aluno aplique, de forma interdisciplinar, conceitos vistos em outras disciplinas de um curso de graduação de Tecnologia em Banco de Dados, ela propicia condições para a aplicação da proposta chamada Aplicativos Úteis. Tal proposta é composta pelas seguintes etapas: a) Análise de Problemática, b) Apresentação de Proposta de Alternativa de Solução, c) Modelagem do Aplicativo, d) Implementação do Aplicativo, e) Escrita de Artigo. A seguir, cada etapa é pormenorizada.

\section{a) Análise de Problemática}

Alunos do $2^{\circ}$ semestre de um curso de graduação de Tecnologia em Banco de Dados, em geral, possuem smartphones e apresentam certas características interessantes, tais como: comunicam-se pelas redes sociais via seus smartphones; para aprender algo sobre determinado assunto, preferem assistir a vídeos relacionados a ler livros ou apostilas; e apresentam dificuldades de escrita, leitura, interpretação e raciocínio lógico.

Também, nesse semestre, esses mesmos alunos cursam as disciplinas Linguagem de Programação, Engenharia de Software e Modelagem de Banco de Dados. Porém, é necessário que haja algo que os faça aplicar os conceitos ensinados, de forma que a aprendizagem se torne significativa.

Contemplando esse cenário e considerando as características descritas dos alunos, a professora de Lab II propõe a cada aluno que investigue e identifique problemas ou questões de seu cotidiano, fazendo-se a pergunta: "Qual problema poderia ser resolvido ou amenizado se eu desenvolvesse um aplicativo para smartphone voltado para essa questão?".

A análise de problemáticas é feita por dois caminhos: 1) a professora analisa as dificuldades dos alunos, e 2) os alunos analisam as problemáticas existentes em seu dia-a-dia, direcionando um olhar mais atento à sua volta.

\section{b) Apresentação de Proposta de Alternativa de Solução}

Uma vez identificado e escolhido um problema, o aluno deve apresentar sua proposta de solução aos seus pares e professora responsável. Um dos intuitos desta etapa é desenvolver no aluno suas capacidades de argumentação e de raciocínio, pois ele deve explicar porque a questão é um problema, relatar as consequências de não se ter uma solução para aquele problema, descrever como um aplicativo para celular poderia ser útil naquele contexto.

As ideias devem ser originais, pois mesmo que já existam aplicativos voltados para aquela questão, o aluno deve apresentar algo que melhore o que já existe, ou tenha características 
inexistentes nos outros. Em síntese, o aplicativo do aluno tem que apresentar um diferencial em relação ao que já existe ou ser inédito quanto àquela problemática abordada.

Outro intuito dessa etapa é fazer com que os alunos desenvolvam sua capacidade de interação, pois os alunos e professora emitem sugestões sobre as ideias apresentadas. A troca de sugestões enriquece as ideias iniciais e previne excessos.

\section{c) Modelagem do Aplicativo}

Definida a problemática tratada no aplicativo, o aluno deve utilizar os conceitos adquiridos nas disciplinas de Engenharia de Software e Arquitetura e Modelagem de Banco de Dados para fazer a modelagem de seu aplicativo. Nessa etapa, o aluno faz uma espécie de planejamento de seu aplicativo, definindo público alvo, dados a serem armazenados, requisitos necessários, casos de uso, desenho de telas do aplicativo.

Também, nessa etapa, o aluno deve escolher ferramentas de software apropriadas para utilização na modelagem e na implementação do aplicativo. Assim, o aluno vai tornando-se agente de sua aprendizagem, pois é ele quem toma as decisões referentes ao aplicativo, ainda que auxiliado pelos professores.

\section{d) Implementação do Aplicativo}

Na etapa de implementação, o aluno enfrenta várias dificuldades e tem de usar sua capacidade de raciocínio lógico para resolver os bugs encontrados. A disciplina Linguagem de Programação fornece as técnicas que o aluno poderá empregar no desenvolvimento do código de seu aplicativo.

Além do raciocínio lógico, nessa etapa, o aluno desenvolve a paciência, a persistência, a capacidade de concentração e o senso investigativo. Essa etapa, apesar de ser considerada a mais árdua, geralmente, é a que os alunos se sentem mais envolvidos e comprometidos, pois eles já têm a noção de que estão desenvolvendo algo próprio. Assim, eles continuam a enfrentar as dificuldades encontradas para ver pronto algo que eles mesmos conceberam.

\section{e) Escrita de Artigo}

Depois de finalizada a etapa de implementação, os alunos devem escrever um artigo, no formato científico, relatando suas ideias, aplicativo desenvolvido, dificuldades encontradas, enfim, descrever as experiências vividas. $\mathrm{O}$ intuito desta etapa é fazer com que o aluno reflita sobre o caminho percorrido até a finalização do aplicativo, com destaque para os conceitos que ele teve de estudar, relembrar ou aprender. Também, nessa reflexão, o aluno percebe que 
para gerar um produto, ele uniu o que aprendeu nas várias disciplinas do curso, suas experiências próprias e seu olhar atento para a realidade.

Dessa forma, o aluno percebe que, por meio de seus estudos, é possível gerar algo útil para a sociedade, ou mesmo para si. Além disso, nessa etapa, alunos, que nunca tiveram a oportunidade de escrever algo mais formal, têm a oportunidade de desenvolver sua escrita, por meio da elaboração de um artigo científico.

\section{RESULTADOS OBTIDOS}

O processo foi aplicado a trinta alunos do curso de graduação de Tecnologia em Banco de Dados, no período noturno, no segundo semestre de dois mil e dezesseis, em uma faculdade pública do estado de São Paulo. Os alunos têm idades entre vinte e quarenta anos e cada um deles teria que cumprir as cinco etapas do processo de ensino-aprendizagem, descrito neste artigo. Inicialmente, surgiram vinte e seis ideias de aplicativos, dentre as quais se destaca o aplicativo Urban Flooding App, cujas etapas de desenvolvimento são utilizadas para ilustrar todo o processo.

\section{a) Análise de Problemática}

Nas áreas urbanas, o crescimento desordenado aumenta os níveis de risco de desastres naturais associados a deslizamentos, enchentes e inundações. Em muitas cidades brasileiras, tem ocorrido a ocupação inadequada de áreas suscetíveis a tais processos, o que tem causado o crescimento de áreas de risco e o número de acidentes com perdas materiais e, sobretudo, de vidas humanas(CARVALHO, C. S.; MACEDO, E. S.; OGURA, 2007).

Em 2013, no Brasil, foi relatada a ocorrência de 493 desastres naturais, sendo 4.433 municípios atingidos (CENAD, 2014). A Tabela 1 apresenta um resumo sobre os danos humanos causados somente por eventos relacionados aos hidrometeorológicos, exceto estiagem.

Tabela 1. Danos humanos por tipo de eventos hidro-meteorológicos.

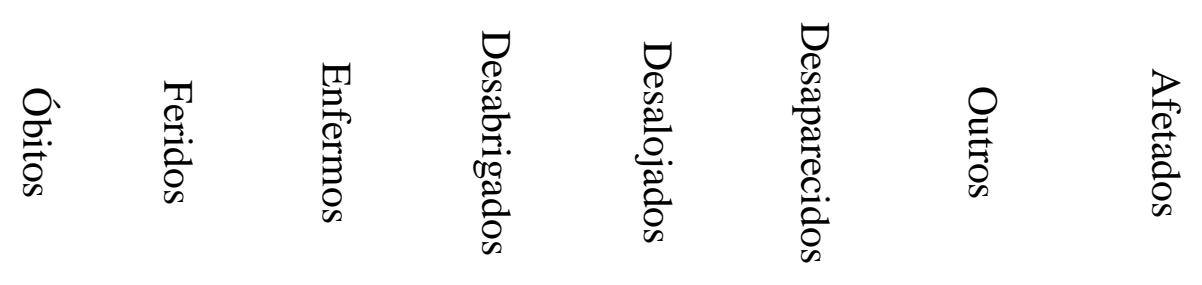

\begin{tabular}{ccccccccc}
\hline Alagamentos & 4 & 279 & 4306 & 44330 & 48260 & 0 & 180641 & 277820 \\
Chuvas intensas & 30 & 468 & 3607 & 25585 & 103278 & 5 & 1604303 & 1737276 \\
Deslizamentos & 41 & 133 & 88 & 6721 & 8843 & 0 & 219530 & 233356 \\
\hline O Rev. Inter. Educ. Sup. & \multicolumn{1}{|l|}{ Campinas, SP } & v.4 & n.3 & p.610-630 & set./dez. 2018 \\
\hline
\end{tabular}




\section{Educação Superior [RIESup]}

\begin{tabular}{ccccccccc} 
Enxurradas & 38 & 787 & 2324 & 17266 & 118074 & 92 & 778694 & 931608 \\
Erosão & 1 & 86 & 466 & 2826 & 3964 & 0 & 343906 & 351249 \\
Inundações & 36 & 1461 & 13283 & 59023 & 208274 & 6 & 1083402 & 1365485 \\
\hline Total & 150 & 3214 & 24074 & 155751 & 490693 & 103 & 4210476 & 4884461 \\
\hline
\end{tabular}

Fonte: Adaptada de (CENAD, 2014).

De acordo com a Tabela 1, em 2013, no Brasil, houve 4.884.461 pessoas afetadas por eventos hidro - meteorológicos, cerca de $30 \%$ do total de vítimas de todos os desastres naturais ocorridos naquele ano. Impactos deste tipo causam um prejuízo anual de mais de $\mathrm{R} \$$ 762 milhões em escala nacional (ARANTES, 2013).

A partir da problemática apresentada pela aluna, a professora analisou a pertinência do assunto e conclui que, de fato, o assunto possui relevância. Ademais, a análise de desastres naturais propicia a reflexão sobre os problemas ambientais, isto é, pode-se raciocinar e investigar até que ponto desastres naturais são realmente naturais ou se eles são consequências de problemas ambientais causados pela ação humana. Tal discussão pode ser usada como meio para conscientizar ou sensibilizar as pessoas sobre as atitudes que causam impacto na sua própria vida, contribuindo para o desenvolvimento de raciocínio crítico (SANTOS, O. R., 2016).

\section{b) Apresentação de Proposta de Alternativa de Solução}

Considerando a ocorrência cada vez mais frequente de eventos associados a desastres naturais e os prejuízos acarretados, analisa-se que, se a população e órgãos competentes tivessem acesso à alertas de riscos com antecedência, medidas preventivas poderiam ser adotadas. Assim, foi proposto o desenvolvimento de um sistema colaborativo para auxiliar o gerenciamento de riscos de desastres ambientais de cunho hidrometeorológico. $\mathrm{O}$ intuito é que o sistema permita que os órgãos responsáveis, por exemplo, retirem pessoas alojadas em áreas de risco, de modo mais rápido que o comumente usado. Tal sistema, em forma de aplicativo para dispositivo móvel, deve apresentar recursos para postagem, consultas e informações aos usuários.

Analisando a alternativa de solução apresentada, alunos e professora opinaram que a sugestão seria plausível, mas que um sistema completo de gerenciamento de riscos demandaria recursos como servidor de dados interligado aos órgãos responsáveis e equipes de resgate, disponíveis em tempo integral. Feitas essas considerações e analisando que esses itens estão fora do escopo da proposta Aplicativos Úteis, a aluna prontificou-se a desenvolver o aplicativo em si. 


\section{c) Modelagem do Aplicativo}

A fim de desenvolver um aplicativo que pudesse atender aos requisitos necessários, foram modelados os casos de uso e o banco de dados. Casos de uso referem-se a um mapeamento entre atores e sistema, tendo por finalidade evitar erros de especificação de software (CARVALHO, 2002). Considerando a relevância de tal fase, a Figura 1 apresenta os casos de usos mapeados para o aplicativo o Urban Flooding.

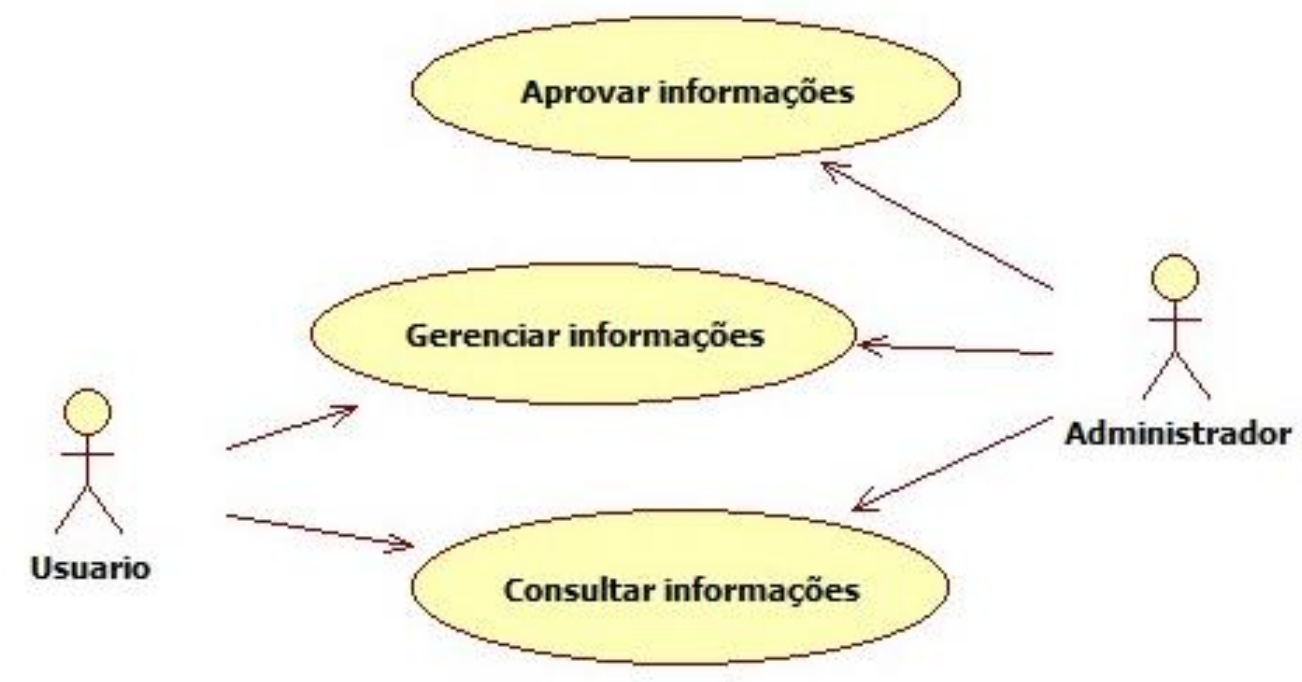

Figura 1. Casos de uso do aplicativo Urban Flooding App.

Fonte: Os autores.

A Figura 1 apresenta dois atores, isto é, pessoas que atuam no sistema: a) usuário comum e b) usuário administrador. Um usuário comum, via smartphone, poderá gerenciar e consultar informações. O administrador do aplicativo, além de acessá-lo da mesma forma que um usuário comum, ainda poderá aprovar ou não as informações recebidas. Cabe ao administrador do aplicativo, portanto, verificar a veracidade e validade de determinada informação. Assim, um usuário comum poderá ter maior confiabilidade nas informações consultadas.

Outro item importante da modelagem do aplicativo refere-se aos dados que devem ser armazenados, isto é, como deve ser o banco de dados. Uma forma de fazer um protótipo do banco de dados é elaborar um Modelo Entidade - Relacionamento (MER). Tal modelo descreve as entidades, seus atributos e as relações entre elas (ALEXANDRUK, 2011). A Figura 2 mostra o MER confeccionado para o aplicativo Urban Flooding. 


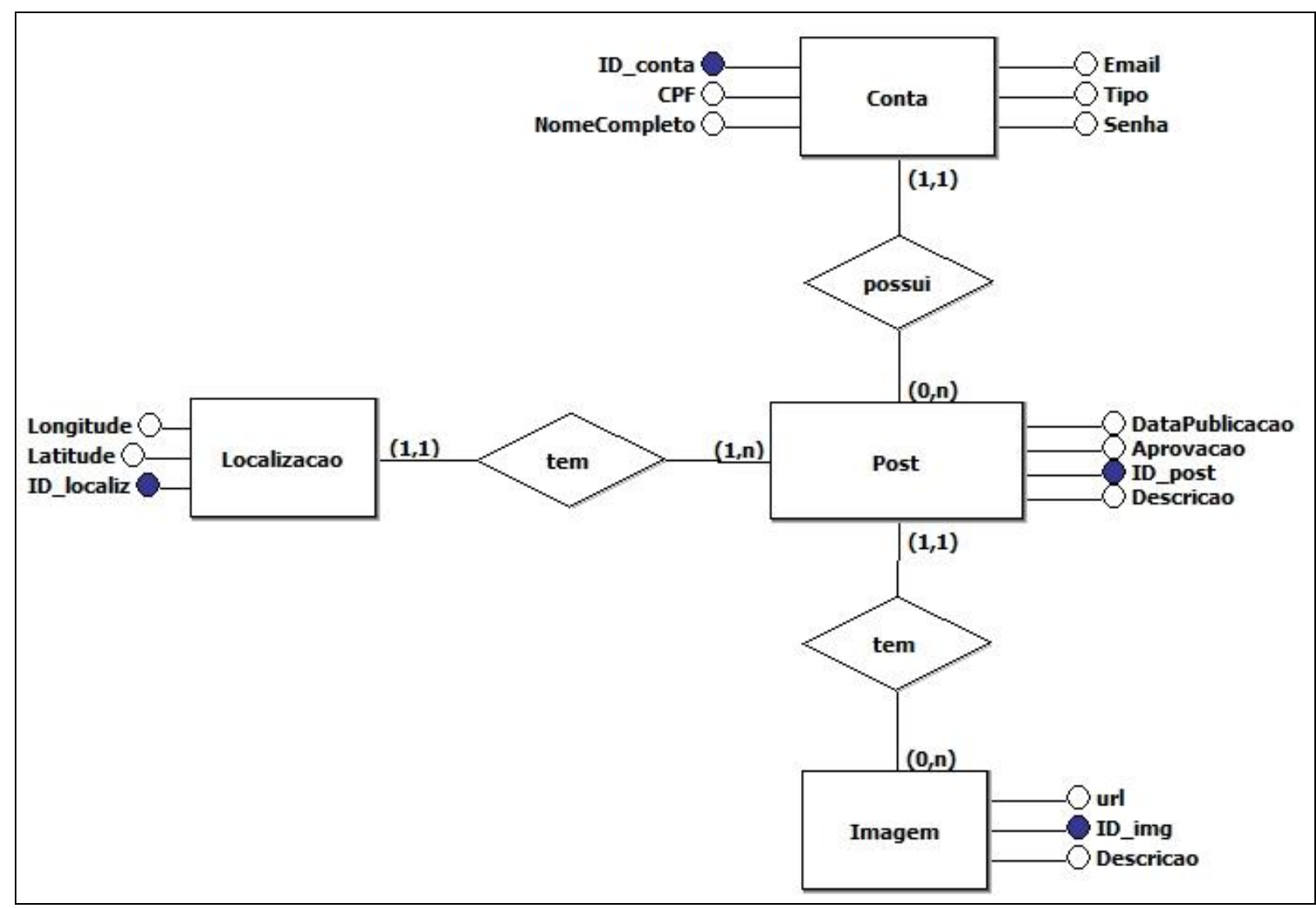

Figura 2. Modelo Entidade -Relacionamento do Urban Flooding.

Fonte: Os autores.

Na Figura 2, cada retângulo simboliza uma entidade, isto é, algo sobre o qual se deseja armazenar dados. Nesse caso, deseja-se armazenar dados sobre Conta, Post, Localização e Imagem. Cada entidade possui atributos, isto é, características cujos valores são os dados a serem armazenados. Por exemplo, considerando uma Localização, deseja-se armazenar os valores dos atributos Longitude, Latitude e ID_localiz. O último atributo tem por finalidade atribuir uma identificação única para cada localização, evitando duplicações de armazenamento.

Nessa etapa do desenvolvimento, as disciplinas Engenharia de Software e Modelagem de Banco de Dados forneceram os insumos teóricos para que a aluna pudesse fazer a modelagem de seu aplicativo. Tal situação veio ao encontro do que foi planejado pela professora de LabII.

\section{d) Implementação do Aplicativo}

Para desenvolver o aplicativo denominado Urban Flooding, utilizou-se a ferramenta MIT App Inventor. Essa ferramenta é um ambiente de programação visual para criar aplicativos para smartphones e tablets, baseados em sistema operacional Android (PERDIKURI, 2014). 


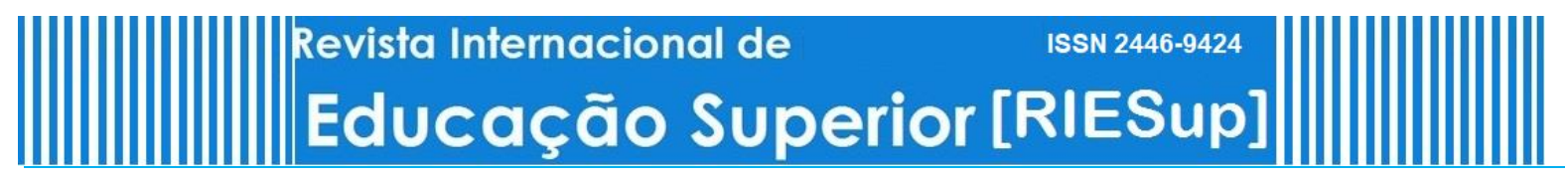

Artigo

DOI: $10.20396 /$ riesup.v4i3.8652076

MIT App Inventor permite o desenvolvimento de aplicativos que contenham bancos de dados, mapas interativos e outros conceitos avançados, sem que o desenvolvedor do aplicativo precise escrever o código, bastando que ele empregue a lógica de programação de forma coerente para o que deseja fazer. Google Labs foi a criadora dessa aplicação de código aberto, que hoje é mantida pelo Massachusetts Institute of Technology (MIT) (WOLBER et al., 2011).

Uma vez definidas as ferramentas de desenvolvimento, o aplicativo Urban Flooding foi desenvolvido e finalizado. A Figura 3 apresenta a tela de inicial do aplicativo.

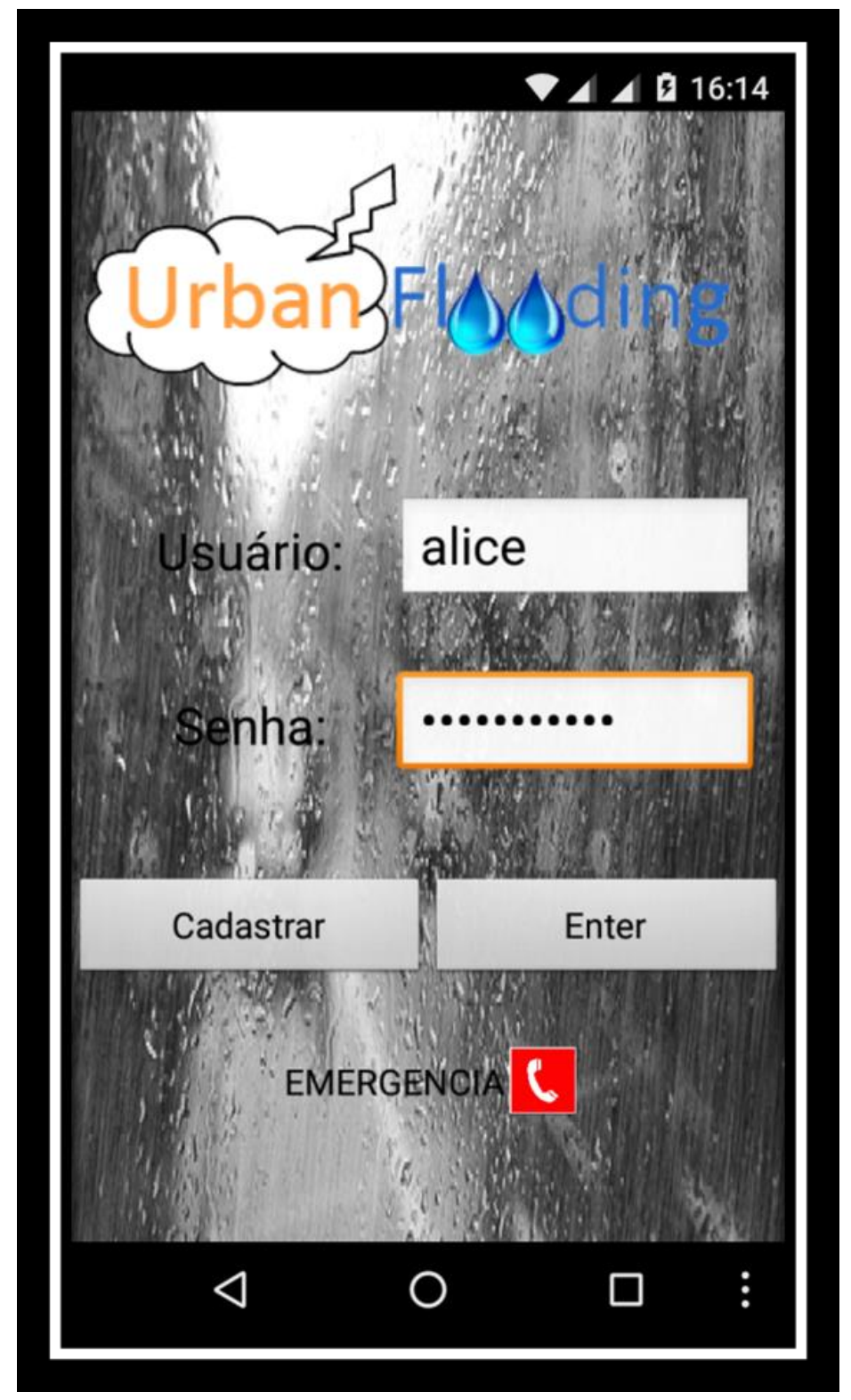

Figura 3. Tela inicial.

Fonte: Os autores.

n. 3 
Conforme a Figura 3, a tela inicial permite que o usuário se cadastre ou acesse o sistema por meio de seu login e senha, previamente cadastrados. Nessa tela, há também um ícone para que o usuário faça a ligação para um número de telefone de emergência.

Uma vez conectado ao sistema, um menu denominado Seções é apresentado ao usuário. Tal menu contém as opções de cadastro, postagens e informações técnicas relevantes. Ainda na mesma tela, há o menu Previsões, por meio do qual o usuário pode verificar previsões das condições do tempo. A Figura 4 apresenta essa tela.

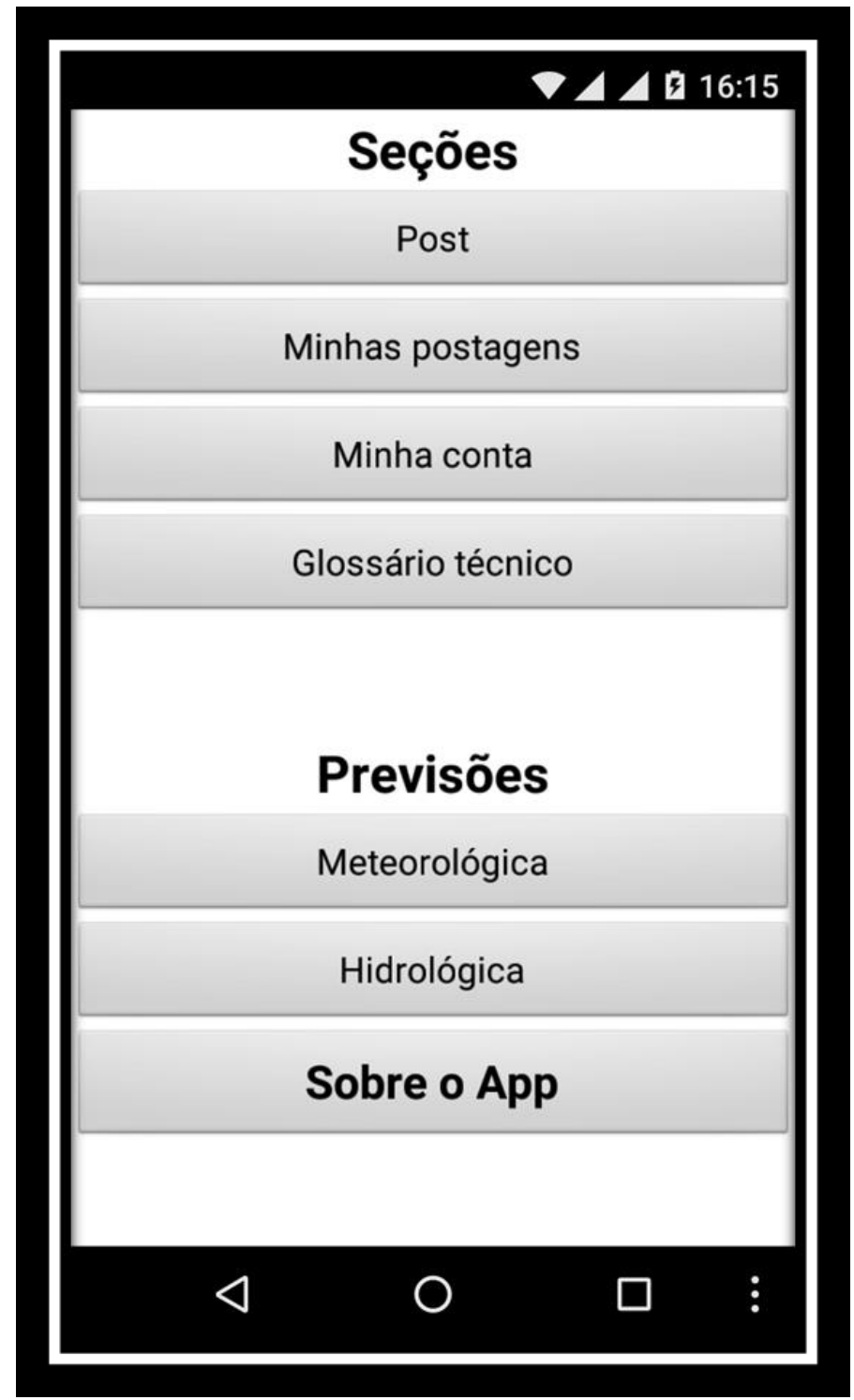

Figura 4. Tela de menus. Fonte: Os autores.

De acordo com a Figura 4, nota-se a existência dos botões Meteorológica, Hidrológica e Sobre o App. Tais botões, ao serem clicados, direcionam o usuário para as páginas oficiais de 
previsão meteorológica, previsão hidrológica e a visualização de informações referentes ao aplicativo Urban Flooding, respectivamente.

Considerando ainda a Figura 4, há os botões Post, Minhas postagens, Minha conta e Glossário técnico. Ao se clicar no botão Post, a tela de "Criar post" será apresentada ao usuário, o qual poderá realizar a inserção de informações relativas ao que se deseja relatar. A Figura 5 exibe essa tela.

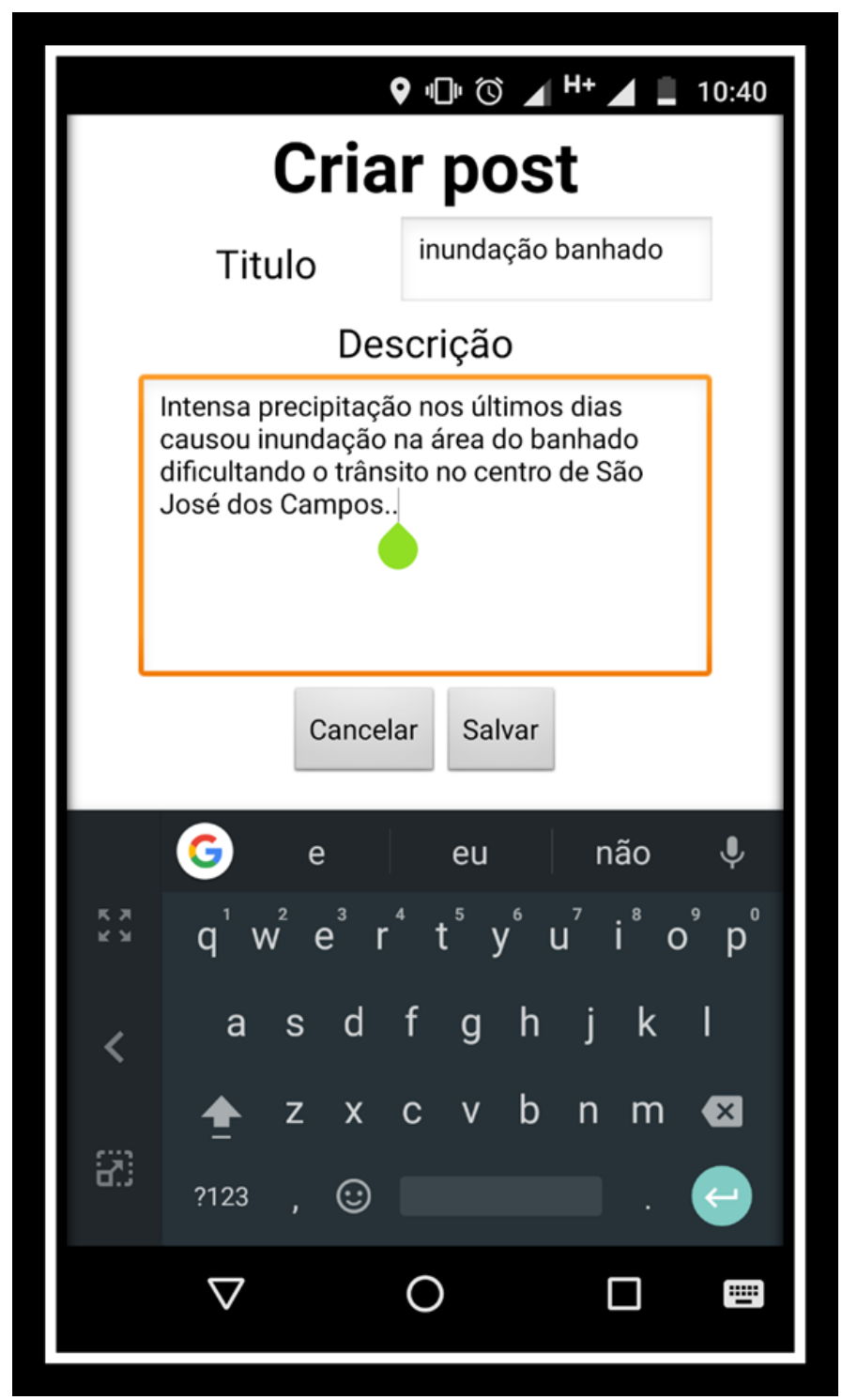

Figura 5. Nova Postagem.

Fonte: Os autores.

Conforme Figura 5, o usuário, ao criar uma postagem, deve fornecer o título e descrição do evento ocorrido. No exemplo da Figura 5, a postagem refere-se a uma inundação em um ponto turístico da cidade de São José dos Campos, estado de São Paulo. 


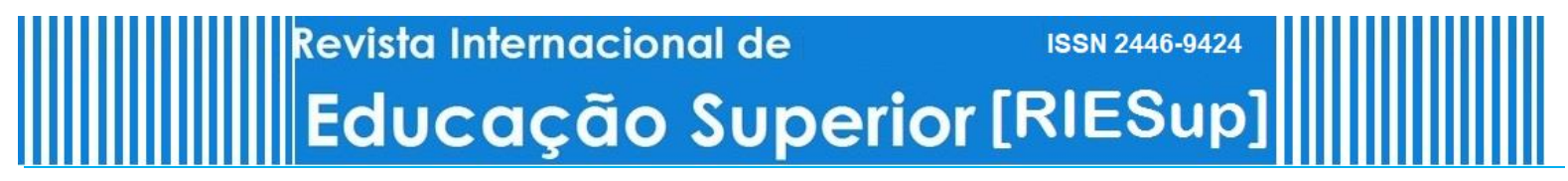

Artigo

DOI: $10.20396 /$ riesup.v4i3.8652076

Após salvar as informações, o usuário terá acesso novamente à tela apresentada na Figura 4. Clicando no botão Minhas Postagens, o usuário poderá realizar consultas sobre as postagens submetidas por ele. A Figura 6 ilustra que o usuário pode visualizar um histórico sobre os desastres ambientais relatados por ele.

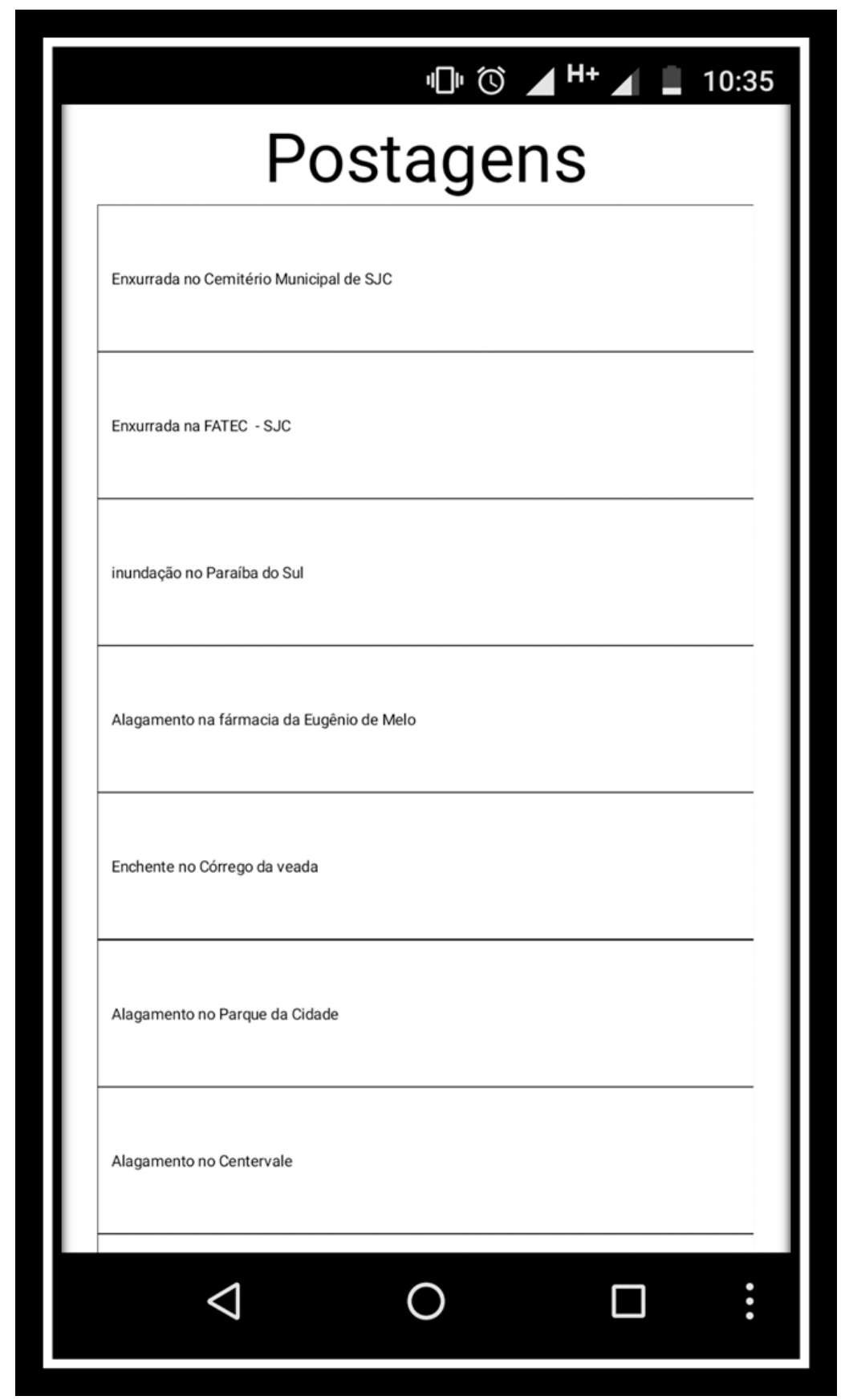

Figura 6. Postagens

Fonte: Os autores. 
A Figura 6 exibe as últimas postagens ocorridas. Caso o usuário queira editar alguma dessas postagens, basta que ele clique no título escolhido da lista apresentada e uma tela de edição é exibida. $\mathrm{O}$ intuito da existência desse recurso é permitir que usuários pudessem atualizar as condições de determinados eventos de forma colaborativa. Por exemplo, um usuário 1 postou o evento "Alagamento no Parque da Cidade" e descreveu que isso está causando engarrafamento de carros na rua $\mathrm{X}$. Um usuário 2 pode editar a postagem desse evento e acrescentar que o congestionamento de veículos chega a três quilômetros nas ruas $\mathrm{X}, \mathrm{Y}$ e Z . Assim, as informações são atualizadas de forma mais dinâmica.

Com o término desta etapa, os alunos têm condições de fazer uma reflexão sobre todo o caminho percorrido, durante o semestre. Tal análise perpassa por avaliar se houve aprendizagem, se foi agradável desenvolver o aplicativo, se as ferramentas escolhidas foram apropriadas, se ocorreu a percepção de que as várias disciplinas do curso querem tratar partes separadas de uma mesma realidade.

\section{e) Escrita de Artigo}

Após desenvolver e testar o aplicativo Urban Flooding, os alunos envolvidos escreveram um artigo, relatando sua experiência de aprendizagem. Um trecho das considerações finais do artigo, referente ao Urban Flooding App, apresenta-se a seguir:

\footnotetext{
"A plataforma do App Inventor ainda é muito instável, focada para desenvolver aplicativos educativos (...). No entanto, deve-se ressaltar que a interface é simples e intuitiva (...). Quanto à proposta inicial, ela demanda tempo de execução, pesquisa, e um sistema gerenciador de banco de dados melhor estruturado. Por isso, para trabalhos futuros, pretende-se desenvolver essa proposta em plataforma independente (...).
}

Nesta etapa, os alunos sentem-se vitoriosos, pois conseguiram traçar e alcançar um objetivo. Eles ganham uma nova visão a respeito das disciplinas do curso, pois elas passam a ter um sentido prático. Também, alunos relatam a satisfação em desenvolver algo que eles mesmos conceberam, tornando-os mais persistentes por aprender o que for necessário para finalizar o aplicativo.

\section{CONSIDERAÇÕES FINAIS}

Este artigo apresentou um processo de ensino - aprendizagem composto de cinco etapas, sendo que, em cada uma delas, o aluno aprimorou ou aprendeu um conjunto de conceitos e tópicos, relativos ao seu cotidiano e às disciplinas estudadas. 
Em cada etapa, estratégias pedagógicas foram utilizadas de forma a promover uma aprendizagem significativa para o aluno. $\mathrm{O}$ aluno estabeleceu uma conexão entre a sua realidade e os conhecimentos adquiridos no curso de graduação. Smartphones deixaram de ser instrumentos de distração, por vezes, um problema para professores, para se tornarem ferramentas de trabalho e teste de aplicativos.

Tanto alunos quanto professora aprenderam com o processo, estreitaram os laços de confiança e diálogo entre as si. Os alunos descobriam que, ainda que sejam limitados em relação à aprendizagem de certos tópicos, com persistência e dedicação, eles podem ir além do que imaginam.

Mais uma vez, a professora de LabII comprovou que alunos, quando se sentem desafiados e instigados, produzem resultados interessantes e úteis, como é o caso do aplicativo Urban Flooding e de outros também resultantes desse trabalho. Dentre os vinte aplicativos implementados, o Urban Flooding foi selecionado como exemplo devido aos alunos, desenvolvedores do aplicativo, terem atingidos todos os objetivos do processo de ensinoaprendizagem proposto. Além disso, o aplicativo em questão pode auxiliar órgãos responsáveis até mesmo no aprimoramento e gestão de políticas públicas, para combate aos desastres naturais decorrentes de eventos hidro - meteorológicos.

Como trabalhos futuros, fica a proposta de desenvolvimento de aplicativos por meio de ambientes mais robustos, tais como Android Studio. Os alunos poderiam acrescentar novas funcionalidades aos seus aplicativos.

\section{REFERÊNCIAS}

ALEXANDRUK, Marcos. Modelagem de banco de dados. Unilivros, , 2011. Disponível em: <http://www.unilivros.com.br/pdf/dbmod.pdf>. Acesso em: 19 jan. 2018.

ARANTES, José Tadeu. Prejuízo ao país com enchentes em São Paulo ultrapassa R\$ 762 milhões por ano. 2013. Disponível em:

<http://agencia.fapesp.br/prejuizo_ao_pais_com_enchentes_em_sao_paulo_ultrapassa_r_762 _milhoes_por_ano/16968/>. Acesso em: 19 jan. 2018.

ARAÚJO, Raul; BELIAN, Rosalie. Concepções de Professores Universitários Sobre Inovação Pedagógica. Revista Internacional Educação Superior, Campinas, SP, v. 4, n. 2, p. 387-400, 2018. Disponível em:

<https://periodicos.sbu.unicamp.br/ojs/index.php/riesup/article/view/8651698/17838> .

Acesso em: 08 maio 2018.

AUSUBEL, David P. Aquisição e retenção de conhecimentos: uma perspectiva Cognitiva. Lisboa: Plátano, 2003. Disponível em: <http://files.mestrado-em-ensino-de-

\begin{tabular}{|l|c|c|c|c|c|}
\hline C Rev. Inter. Educ. Sup. & Campinas, SP & v.4 & n.3 & p.610-630 & set./dez. 2018 \\
\hline
\end{tabular}


ciencias.webnode.com/200000007-610f46208a/ausebel.pdf>. Acesso em: 08 jan. 2018.

BACICH, Lilian; MORAN, José. Metodologias ativas para uma educação inovadora: uma abordagem teórico-prática. Porto Alegre: Penso, 2018.

CARVAlHO, C. S.; MACEDO, E. S.; OGURA, A. T. (Org). Mapeamento de riscos em encostas e margem de rios. Brasília: Ministério das Cidades e Instituto de Pesquisas Tecnológicas - IPT, 2007. Disponível em:

<http://www.cidades.gov.br/images/stories/ArquivosSNPU/Biblioteca/PrevencaoErradicacao/ Livro_Mapeamento_Enconstas_Margens.pdf>. Acesso em: 08 jan. 2018.

CARVALHO, Maria Cristina Ferro. Um método para elicitação e modelagem de requisitos baseado em objetivos. São LuisUniversidade Federal do Maranhão, 2002. Disponível em: <https://tedebc.ufma.br/jspui/bitstream/tede/307/1/Marcia Cristina Ferro Carvalho.pdf>. Acesso em: 08 jan. 2018.

CENAD. Anuário Brasileiro de Desastres Naturais: 2013. Brasília: Ministério da Integração Nacional. Secretaria Nacional de Proteção e Defesa Civil. Centro Nacional de Gerenciamento de Riscos e Desastres., 2014. Disponível em:

<http://www.mi.gov.br/c/document_library/get_file?uuid=fee4007a-ab0b-403e-bb1a8aa00385630b\&groupId=10157>. Acesso em: 08 jan. 2018.

FERREIRA, Giselle Martins dos Santos; FREITAS, Rejane Cunha; MOREIRA, Laélia Carmelita Portela. Inovação, TIC e docência: práticas e concepções de professores em uma IES privada. Revista Internacional de Educação Superior, Campinas, SP, v. 4, n. 1, p. 2551, 2018. Disponível em:

<https://periodicos.sbu.unicamp.br/ojs/index.php/riesup/article/view/8650880>. Acesso em: 08 maio 2018.

FRAGELLI, Thaís Branquinho Oliveira. Gamificação como um processo de mudança no estilo de ensino aprendizagem no ensino superior: um relato de experiência. Revista

Internacional de Educação Superior, Campinas, SP, v. 4, n. 1, p. 221-233, 2017.

Disponível em:

<https://periodicos.sbu.unicamp.br/ojs/index.php/riesup/article/view/8650843>. Acesso em: 08 maio 2018.

JORGE, Juliana Gomes et al. Influence of passive smoking on learning in elementary school. Jornal de Pediatria, [s. 1.], v. 92, n. 3, p. 260-267, 2016. Disponível em: <http://dx.doi.org/10.1016/j.jpedp.2016.02.012>. Acesso em: 08 jan. 2018.

LIMA, Franciele Santos De; ZAGO, Nadir. Desafios conceituais e tendências da evasão no ensino superior: a realidade de uma universidade comunitária. Revista Internacional de Educação Superior, Campinas, SP, v. 4, n. 2, p. 366-386, 2018.

MARIM, Vlademir; FREITAS, Adriano Vargas; SANTOS, Heinrich da Solidade. a Formação De Professores Na Era Da Inclusão Digital. Revista Contexto \& Educação, [s. 1.], 
v. 29, n. 94, p. 153-178, 2014.

MELO-SOLARTE, Diego Samir; BARANAUSKAS, M. Cecília C. Uma abordagem para EaD Baseada em Resolução de Problemas. [s. 1.], n. Sbie 2008, p. 716-725, [s.d.].

MORAN, José. Metodologias ativas para uma aprendizagem mais profunda. [s.l: s.n.]. Disponível em: <http://www2.eca.usp.br/moran/wp-

content/uploads/2013/12/metodologias_moran1.pdf>. Acesso em: 08 mai. 2018.

NETO, Francisco Frederico et al. Dificuldade de aprendizagem no ensino fundamental e médio: a percepção de professores de sete escolas públicas de São Paulo - SP. Rev.

Psicopedagogia, [s. 1.], v. 32, n. 97, p. 26-37, 2015.

NOGARO, Arnaldo; CERUTTI, Elisabete. As TICs nos labirintos da prática educativa. Curitiba: Editora CRV, 2016.

NOGUEIRA, Teresinha De Fátima; MARTINEZ, Juliana Forin Pasquini; OLIVEIRA, Angélica Gomes De. Jogos para celular: uma experiência interdisciplinar na aprendizagem de língua inglesa. In: CONGRESSO BRASILEIRO DE LÍNGUAS ESTRANGEIRAS NA FORMAÇÃO TÉCNICA E TECNOLÓGICA, 3., 2016, São Bernardo do Campo. Anais... [S.l. : s.n.], 2016.

PENSIN, Daniela Pederiva. Educação superior e agenciamento: a constituição singular do professor da educação superior no presente. Revista Internacional de Educação Superior, Campinas, SP, v. 4, n. 1, p. 74, 2018. Disponível em:

<https://periodicos.sbu.unicamp.br/ojs/index.php/riesup/article/view/8650674>. Acesso em: 08 maio 2018.

PERDIKURI, Katerina. Students' Experiences from the use of MIT App Inventor in classroom. In: PROCEEDINGS OF THE 18TH PANHELLENIC CONFERENCE ON INFORMATICS - PCI '14 2014, New York, New York, USA. Anais... New York, New York, USA: ACM Press, 2014. Disponível em:

<http://dl.acm.org/citation.cfm?doid=2645791.2645835>. Acesso em: 08 jan. 2018.

REIS, Bia. Cortella: "A escola passou a ser vista como um espaço de salvação". O Estado de São Paulo, [s. 1.], 2014. Disponível em:

$<$ http://educacao.estadao.com.br/noticias/geral,cortella-a-escola-passou-a-ser-vista-como-umespaco-de-salvacao,1168058>. Acesso em: 08 mai. 2018.

SALES, Shirlei Rezende; LEAL, Rafaela Esteves Godinho. Práticas pedagógicas inovadoras na formação docente: ciborguização do currículo do curso de pedagogia. Revista

Internacional de Educação Superior, Campinas, SP, v. 4, n. 1, p. 7-24, 2018. Disponível em: <https://periodicos.sbu.unicamp.br/ojs/index.php/riesup/article/view/8650710>. Acesso em: 08 maio 2018.

SANTOS, Orildo Ribeiro. Um olhar de alunos da eja sobre impactos ambientais do turismo 
costeiro em ajuruteua (Bragança-PA). Revista Contexto \& Educação, [s. 1.], v. 31, n. 100, p. 116-139, 2016. Disponível em: <https://www.revistas.unijui.edu.br/index.php/ contextoeducacao/article/view/5736>. Acesso em: 08 jan. 2018.

SILVA, Simone Vieira Da. As principais causas das dificuldades de aprendizagem em alunos da rede municipal de Sinop atendidos pelo instituto criança. Eventos Pedagógicos, [s. 1.], v. 7, n. 3, p. 1321-1332, 2016.

SILVA JR., Romualdo. Indicadores acerca da importância do papel do professor no processo de formação continuada do aluno: um ensaio a partir da Teoria da Aprendizagem

Significativa de David Ausubel. Revista Thema, [s. 1.], v. 14, n. 2, p. 329-335, 2017.

Disponível em: <http://revistathema.ifsul.edu.br/index.php/thema/article/view/410>. Acesso em: 08 jan. 2018.

THIESEN, Juares da Silva. A interdisciplinaridade como um movimento articulador no processo ensino-aprendizagem. Revista Brasileira de Educação, [s. 1.], v. 13, n. 39, p. 545554, 2008. Disponível em: <http://www.scielo.br/pdf/rbedu/v13n39/10.pdf>. Acesso em: 08 jan. 2018.

WOLBER, David et al. App Inventor Create Your Own Android Apps. Sebastopol: O’Reilly Media, Inc, 2011. Disponível em:

<http://cs.usfca.edu/ wolber/appinventor/appinv_0331.pdf>. Acesso em: 08 jan. 2018.

\section{Sobre os autores}

1 Adriana da Silva Jacinto

E-mail: adriana.jacinto@ fatec.sp.gov.br

Fatec de São José dos Campos Professor Jessen Vidal - Brasil

Doutora em Ciências - Engenharia da Computação pelo ITA.

\section{${ }^{2}$ Alice Nardoni Marteli}

E-mail: alicenmart2@gmail.com

Instituição - País Fatec de São José dos Campos Professor Jessen Vidal - Brasil

Mestrado em Engenharia Civil da Universidade Estadual Paulista [UNESP].

\section{${ }^{3}$ João Gabriel Dias Pires}

E-mail: joao.pires@fatec.sp.gov.br

Instituto Federal de São Paulo (Ararquara) - Brasil

Cursando Análise e Desenvolvimento de Sistemas pela Fatec São José dos Campos.

\section{Jaqueline da Silva Jacinto $(\mathbb{D}$}

E-mail: jalumiar2@gmail.com

Secretaria de Educação Municipal de São José dos Campos - Brasil

Pós-graduada em Metodologia do Ensino da Língua Portuguesa pela Fac. São Luís de Jaboticabal. 